\title{
Dipole Moment of Poly(ethylene oxide) in Solution and Its Dependence on Molecular Weight and Temperature
}

\author{
By Noriko YAMAGUCHI and Mari SATO*
}

The dipole moment of poly(ethylene oxide) (PEO) and its dependence on molecular weight and temperature have been investigated by measuring the dielectric constant and the density of dilute PEO-benzene solutions in the temperature range from 25 to $55^{\circ} \mathrm{C}$. The dipole moments of the polymers $\left\langle\mu_{\text {molecule }}{ }^{2}\right\rangle^{1 / 2}$, increased linearly with respect to the square root of the degree of polymerization $n$, which confirms the theoretical prediction that the long-range excluded volume interactions have little effect on the dipole moment of polymers such as PEO. The estimated value for diethyl ether $\mu_{\mathrm{DE}}$ is $1.20 \mathrm{D}$, according to the relationship between $\left\langle\mu_{\text {molecule }}{ }^{2}\right\rangle^{1 / 2}$ and $n^{1 / 2}$ for PEO oligomers, ${ }^{10,17}$ which leads to a C-O bond moment, $m_{\mathrm{C}-\mathrm{O}}$, of $1.07 \mathrm{D}$. The averaged dipole moment per constitutional repeating unit $\left\langle\mu^{2}\right\rangle^{1 / 2}$ for PEO polymers is $1.040 \pm 0.002$ [D] at $25^{\circ} \mathrm{C}$. The following dipole moment ratio and the temperature coefficient were obtained for PEO in benzene: $\left\langle\mu^{2}\right\rangle / \mathrm{m}^{2}=0.472 \pm 0.002$ (at $25^{\circ} \mathrm{C}$ ) and $\mathrm{d} \ln \left\langle\mu^{2}\right\rangle / \mathrm{d} T=(2.11 \pm 0.28) \times 10^{-3} \mathrm{~K}^{-1}\left(25-45^{\circ} \mathrm{C}\right)$. The experimental results are compared with the conformational characteristics of PEO investigated by the rotational isomeric state (RIS) analyses by Abe et al. and Sasanuma et al.

KEY WORDS: Dipole Moment / Molecular Weight Dependence / Dipole Moment Ratio / Temperature Dependence / Poly(ethylene oxide) / Bond Moment / Dilute Solution /

Poly(ethylene oxide) (PEO) $-\left(\mathrm{CH}_{2} \mathrm{CH}_{2} \mathrm{O}\right)_{\mathrm{n}}-$ chains contain oxygen atoms at every third position of the polymer backbone. The $\mathrm{O}-\mathrm{C}-\mathrm{C}-\mathrm{O}$ bond sequence acts as an effective electron donor, providing the PEO polymer with hydrophilic properties, such as solubility in water as well as in many non-polar organic solvents. ${ }^{1}$ PEO molecules in solution have a large degree of molecular freedom in terms of rotation about the single bonds; therefore, PEO molecules can take numerous conformations in solution. The polymer chain conformation is characterized by a dipole moment equal to the vectorial sum of the moments of its $\mathrm{n}$ monomers. The mean-square dipole moment of the polymer molecule $\left\langle\mu_{\text {molecule }}{ }^{2}\right\rangle$, measured in dilute solution is a quantity dependent on the statistical average of the conformations available to the polymer chains. ${ }^{2}$ The dipole moment possesses some advantages over other conformation-dependent properties such as the mean-square end-to-end distance; some of the skeletal bonds change much more in polarity than they do in length and consequently the dipole moment is more sensitive to structure than the end-to-end distance. ${ }^{3}$ Another advantage of the dipole moment measurement is that, unlike chain dimension, the polymer dipole moment should not be affected by long-range excluded volume interactions if the chain molecule possesses components of dipole moments only in the direction perpendicular to the chain backborn. ${ }^{4}$

Much research has been carried out on the conformationdependent properties of PEO chains using three-state rotational isomeric state (RIS) analysis. In earlier research, the energy parameters of the three isomeric states were estimated based on conventional semi-empirical expressions and were corrected so as to yield the best agreement between the calculated and experimental mean-square dimensions, dipole moments, and their temperature dependence. ${ }^{2,5,6}$

In recent work on the PEO polymer, the RIS energy parameters have been obtained from the experimental NMR vicinal coupling data or ab initio molecular orbital (MO) calculations based on a model compound of the PEO polymer, 1, 2-dimethoxyethane (DME) ${ }^{7-9}$ In these investigations, the molecular conformations of PEO chains were examined in more detail: however, there have been few experimental reports on the dipole moments of polymers, most of which are reports on dihydroxy-terminated poly(oxyethylene) glycols, with low molecular weights up to $c a$. $10000 .{ }^{10-13}$ Furthermore, the reported dipole moments show limited agreement with each other and the data have been insufficient for verification of the RIS calculations.

In order to obtain more reliable data, the present investigation has focused on precise measurement of the dipole moments of PEO in benzene and their dependence on molecular weight and temperature, in addition to measurement of PEO with higher molecular weights, using improved equipment that enables very precise measurement of the dielectric constants of liquids. ${ }^{14}$

\section{EXPERIMENTAL}

\section{Polymer Samples}

Samples of PEO with narrow molecular weight $\left(M_{\mathrm{w}}\right)$ distributions were obtained from Toso Co. Ltd. Seven samples of PEO with $M_{\mathrm{w}}$ ranging from $2.1 \times 10^{4}$ to $86 \times 10^{4}$ were used in the study. The chemical structure of PEO is the alkoxy- and 
Table I. Characteristics of poly(ethylene oxide)

\begin{tabular}{ccc}
\hline Code & $M_{\mathrm{w}} \times 10^{-4}$ & $M_{\mathrm{w}} / M_{\mathrm{n}}$ \\
\hline PEO-2 & 2.1 & 1.12 \\
PEO-5 & 4.6 & 1.10 \\
PEO-10 & 9.5 & 1.04 \\
PEO-17 & 17 & 1.04 \\
PEO-27 & 27 & 1.09 \\
PEO-57 & 57 & 1.10 \\
PEO-86 & 86 & 1.17 \\
\hline
\end{tabular}

hydroxyl-terminated structure, $\mathrm{RO}\left(\mathrm{CH}_{2} \mathrm{CH}_{2} \mathrm{O}\right)_{n} \mathrm{H}$. The manufacturer specifications for $M_{\mathrm{w}}$ and polydispersity indices $\left(M_{\mathrm{w}} / M_{\mathrm{n}}\right)$, which were determined from light scattering, gel permeation chromatography and viscosity measurements, are given in Table I.

\section{Measurements of Dielectric Constants and Density}

Dielectric constants were measured using a General Radio Co. 1620A-type capacitance bridge at a frequency of $10 \mathrm{kHz}$ (at which the dielectric constant is a good approximation for the static value). A three-terminal type electrodes cell was used for the measurements, which consisted of coaxial cylindrical platinum electrodes and a double-walled Pyrex glass tube requiring $c a .50 \mathrm{~mL}$ of solution, its capacitance with air of which was $26.5650 \pm 0.0005 \mathrm{pF}$. Details of the cell have been previously reported. ${ }^{14}$ During the measurements, the cell was surrounded with stainless mesh for shielding and immersed in a silicon oil bath with the temperature thermostatically controlled to $\pm 0.01^{\circ} \mathrm{C}$.

The solvent used for measurements was benzene, which was dried by passing it through a $4 \mathrm{~A}$ molecular sieve and then purified by repeated distillation before use. The densities of the solvent and the polymer solutions were determined using a flask-type capillary pycnometer with a volume of $c a .10 \mathrm{~mL}$. The measurements were carried out at several weight fractions $\mathrm{w}$, in the range of 0.005 to $0.02(\mathrm{~g} / \mathrm{g})$ for each sample over the temperature range from 25 to $55^{\circ} \mathrm{C}$.

\section{RESULTS}

The dipole moments per constitutional repeating unit of the polymer chains $\mu$ were calculated by the conventional method based on the Debye theory using experimentally measured dielectric constants and densities. ${ }^{15}$

The specific polarization of the polymers at infinite dilution $\left(p_{2}\right)$ was calculated according to the Halverstadt-Kumler equation. $^{16}$

$$
p_{2}=p_{1}\left(1+3 \alpha /\left(\varepsilon_{1}-1\right)\left(\varepsilon_{1}+2\right)-\beta / \rho_{1}\right)
$$

with $\alpha=\mathrm{d}\left(\varepsilon_{12}-\varepsilon_{1}\right) / \mathrm{d} w$ and $\beta=\mathrm{d}\left(\rho_{12}-\rho_{1}\right) / \mathrm{d} w$, where $w$ is the weight fraction of the solute, $\varepsilon$ is the dielectric constant, $\rho$ is the density, and subscripts 1,2 and 12 refer to the solvent, solute and solution, respectively.

The specific polarization $p_{2}$ multiplied by the molecular weight $M_{0}$ of the monomeric unit provides the molecular

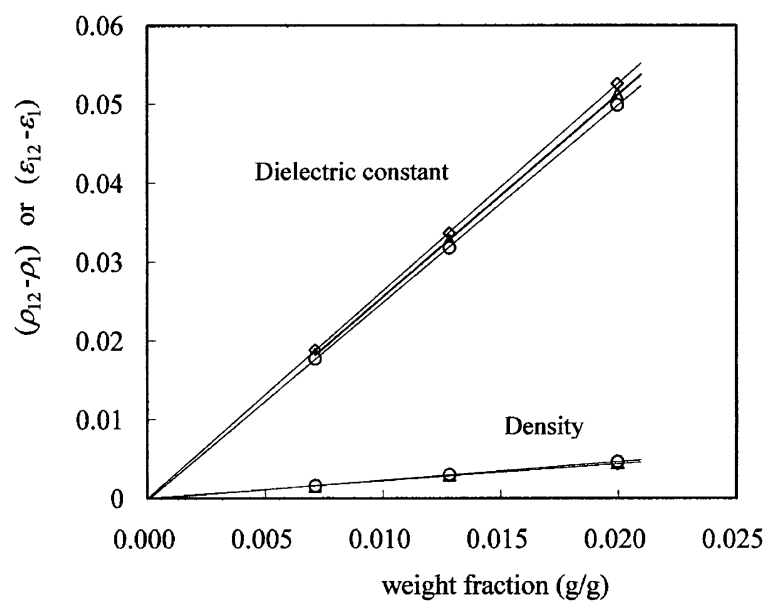

Figure 1. Typical data showing the concentration dependence of the increase in dielectric constant and density for poly(ethylene oxide) PEO-27 in benzene at $25^{\circ} \mathrm{C}(\diamond), 35^{\circ} \mathrm{C}(\triangle)$ and $45^{\circ} \mathrm{C}(\bigcirc)$. ( $\varepsilon=$ dielectric constant, $\rho=$ density, subscripts 1 and 12 refer to the solvent and solution, respectively).

polarization, $P_{2}\left(=M_{0} \times p_{2}\right)$. According to the Debye theory, $P_{2}$ is expressed by:

$$
\begin{aligned}
& P_{2}=\left(4 \pi N_{\mathrm{A}} / 3\right)\left[\gamma+\left(\mu^{2} / 3 k T\right)\right] \\
& P_{2}=P_{\mathrm{O}}+P_{\mathrm{E}}+P_{\mathrm{A}}
\end{aligned}
$$

with $P_{0}=\left(4 \pi N_{\mathrm{A}} / 9 k T\right) \mu^{2}$ and $P_{\mathrm{E}}+P_{\mathrm{A}}=\left(4 \pi N_{\mathrm{A}} / 3\right) \gamma$, where $\gamma$ is the polarizability, $k$ is the Boltzmann constant, $N_{\mathrm{A}}$ is Avogadro's number and $T$ is the temperature. $P_{\mathrm{O}}, P_{\mathrm{E}}$ and $P_{\mathrm{A}}$ are the orientation, electronic and atomic polarizations, respectively. Thus, the average dipole moment per constitutional repeating unit $\mu$ is given:

$$
\mu^{2}=\left[9 k T /\left(4 \pi N_{\mathrm{A}}\right)\right]\left[P_{2}-\left(P_{\mathrm{E}}+P_{\mathrm{A}}\right)\right]
$$

For an estimation of $P_{\mathrm{E}}+P_{\mathrm{A}}$, it was assumed that the molecular refraction for the sodium $\mathrm{D}$ line, $[M R]_{\mathrm{D}}$, is equal to the sum of $P_{\mathrm{E}}+P_{\mathrm{A}}$; in this case, it was calculated from the atomic refraction of constituent atoms. It is considered that $[M R]_{\mathrm{D}}$ includes the contribution from the unknown $P_{\mathrm{A}}$. In some cases, ${ }^{17}$ by approximately estimating $P_{\mathrm{A}}$ as a fixed percentage from 5 to $10 \%$ of $P_{\mathrm{E}}$, the sum of $P_{\mathrm{E}}+P_{\mathrm{A}}$ is assumed to be equal to $1.05-1.10$ times the value of $[M R]_{\mathrm{D}}$. Eq. (4) is thus transformed to:

$$
\mu=0.01281\left\{\left(P_{2}-[M R]_{\mathrm{D}}\right) T\right\}^{1 / 2}
$$

Figure 1 shows typical results for the concentration dependence of the dielectric constant and density of the polymer solutions, indicating the linear relationships for both $\left(\varepsilon_{12}-\varepsilon_{1}\right)$ and $\left(\rho_{12}-\rho_{1}\right)$ as a function of weight fraction $\mathrm{w}(\mathrm{g} / \mathrm{g})$. From these linear relationships, values of $\alpha=\mathrm{d}\left(\varepsilon_{12}-\varepsilon_{1}\right) / \mathrm{d} w$ and $\beta=\mathrm{d}\left(\rho_{12}-\rho_{1}\right) / \mathrm{d} w$ are obtained. In Table II $(\mathrm{a}-\mathrm{g})$, the root mean squared dipole moments evaluated for the constitutional unit, $\left\langle\mu^{2}\right\rangle^{1 / 2}$, of the PEO samples are given together with $\alpha, \beta$, the specific polarization $\mathrm{p}_{2}$ and the molecular polarization $P_{2}$. A value of $[M R]_{\mathrm{D}}=11.065$ was used for the calculation. 
Table II. (a)-(g) Summary of experimental data and dipole moments for poly(ethylene oxide) samples in benzene

(a) PEO-2

\begin{tabular}{|c|c|c|c|c|c|}
\hline Temp. $\left({ }^{\circ} \mathrm{C}\right)$ & $\alpha$ & $\beta$ & $p_{2}$ & $P_{2}$ & $\mu(D)$ \\
\hline 25 & 2.6880 & 0.22383 & 0.75901 & 33.437 & $1.046_{5}$ \\
\hline 30 & 2.6498 & 0.22589 & 0.75603 & 33.305 & $1.052_{2}$ \\
\hline 35 & 2.6116 & 0.22796 & 0.75295 & 33.170 & $1.057_{6}$ \\
\hline 40 & 2.5734 & 0.23003 & 0.74977 & 33.030 & $1.062_{7}$ \\
\hline 45 & 2.5352 & 0.23209 & 0.74649 & 32.885 & $1.067_{7}$ \\
\hline 50 & 2.4970 & 0.23416 & 0.74311 & 32.736 & $1.072_{3}$ \\
\hline 55 & 2.4588 & 0.23622 & 0.73962 & 32.583 & $1.076_{8}$ \\
\hline \multicolumn{6}{|l|}{ (b) PEO-5 } \\
\hline Temp. $\left({ }^{\circ} \mathrm{C}\right)$ & $\alpha$ & $\beta$ & $p_{2}$ & $P_{2}$ & $\mu(D)$ \\
\hline 25 & 2.6368 & 0.22234 & 0.75003 & 33.041 & $1.037_{2}$ \\
\hline 30 & 2.6047 & 0.22558 & 0.74768 & 32.937 & $1.043_{4}$ \\
\hline 35 & 2.5725 & 0.22882 & 0.74524 & 32.830 & $1.049_{4}$ \\
\hline 40 & 2.5404 & 0.23206 & 0.74272 & 32.719 & $1.055_{2}$ \\
\hline 45 & 2.5082 & 0.23530 & 0.74012 & 32.605 & $1.060_{8}$ \\
\hline 50 & 2.4761 & 0.23854 & 0.73743 & 32.486 & $1.066_{1}$ \\
\hline 55 & 2.4439 & 0.24178 & 0.73466 & 32.364 & $1.071_{3}$ \\
\hline \multicolumn{6}{|l|}{ (c) PEO-10 } \\
\hline Temp. $\left({ }^{\circ} \mathrm{C}\right)$ & $\alpha$ & $\beta$ & $p_{2}$ & $P_{2}$ & $\mu(\mathrm{D})$ \\
\hline 25 & 2.6789 & 0.23749 & 0.75201 & 33.128 & $1.039_{3}$ \\
\hline 30 & 2.6376 & 0.23907 & 0.74863 & 32.980 & $1.044_{4}$ \\
\hline 35 & 2.5964 & 0.24065 & 0.74514 & 32.826 & $1.049_{3}$ \\
\hline 40 & 2.5552 & 0.24223 & 0.74155 & 32.667 & $1.053_{9}$ \\
\hline 45 & 2.5140 & 0.24382 & 0.73783 & 32.504 & $1.058_{3}$ \\
\hline 50 & 2.4782 & 0.24540 & 0.73401 & 32.335 & $1.062_{4}$ \\
\hline 55 & 2.4316 & 0.24698 & 0.73007 & 32.162 & $1.066_{2}$ \\
\hline \multicolumn{6}{|l|}{ (d) PEO-17 } \\
\hline Temp. $\left({ }^{\circ} \mathrm{C}\right)$ & $\alpha$ & $\beta$ & $p_{2}$ & $P_{2}$ & $\mu(D)$ \\
\hline 25 & 2.7071 & 0.24801 & 0.75314 & 33.178 & $1.040_{5}$ \\
\hline 30 & 2.6652 & 0.24489 & 0.75151 & 33.106 & $1.047_{5}$ \\
\hline 35 & 2.6233 & 0.24176 & 0.74981 & 33.031 & $1.054_{3}$ \\
\hline 40 & 2.5814 & 0.23864 & 0.74801 & 32.952 & $1.060_{9}$ \\
\hline 45 & 2.5394 & 0.23552 & 0.74612 & 32.869 & $1.067_{3}$ \\
\hline 50 & 2.4975 & 0.23239 & 0.74415 & 32.782 & $1.073_{5}$ \\
\hline 55 & 2.4556 & 0.22927 & 0.74208 & 32.691 & $1.079_{5}$ \\
\hline \multicolumn{6}{|l|}{ (e) PEO-27 } \\
\hline Temp. $\left({ }^{\circ} \mathrm{C}\right)$ & $\alpha$ & $\beta$ & $p_{2}$ & $P_{2}$ & $\mu(\mathrm{D})$ \\
\hline 25 & 2.6356 & 0.22034 & 0.75051 & 33.062 & $1.037_{7}$ \\
\hline 30 & 2.6015 & 0.22379 & 0.74767 & 32.937 & $1.043_{4}$ \\
\hline 35 & 2.5673 & 0.22724 & 0.74474 & 32.808 & 1.0489 \\
\hline 40 & 2.5332 & 0.23068 & 0.74172 & 32.675 & $1.054_{1}$ \\
\hline 45 & 2.4991 & 0.23413 & 0.73860 & 32.538 & $1.059_{1}$ \\
\hline 50 & 2.4649 & 0.23757 & 0.73540 & 32.396 & $1.063_{9}$ \\
\hline 55 & 2.4308 & 0.24102 & 0.73209 & 32.251 & $1.068_{4}$ \\
\hline \multicolumn{6}{|l|}{ (f) PEO-57 } \\
\hline Temp. $\left({ }^{\circ} \mathrm{C}\right)$ & $\alpha$ & $\beta$ & $p_{2}$ & $P_{2}$ & $\mu(D)$ \\
\hline 25 & 2.6642 & 0.22658 & 0.75345 & 33.192 & $1.040_{8}$ \\
\hline 30 & 2.6283 & 0.22743 & 0.75136 & 33.100 & $1.047_{3}$ \\
\hline 35 & 2.5923 & 0.22829 & 0.74919 & 33.004 & $1.053_{6}$ \\
\hline 40 & 2.5563 & 0.22914 & 0.74694 & 32.905 & $1.059_{7}$ \\
\hline 45 & 2.5204 & 0.23000 & 0.74460 & 32.802 & $1.065_{6}$ \\
\hline 50 & 2.4844 & 0.23085 & 0.74217 & 32.659 & $1.071_{3}$ \\
\hline 55 & 2.4485 & 0.23171 & 0.73966 & 32.584 & $1.076_{8}$ \\
\hline \multicolumn{6}{|l|}{ (g) PEO-86 } \\
\hline Temp. $\left({ }^{\circ} \mathrm{C}\right)$ & $\alpha$ & $\beta$ & $p_{2}$ & $P_{2}$ & $\mu(D)$ \\
\hline 25 & 2.6566 & 0.21957 & 0.75476 & 33.249 & $1.042_{1}$ \\
\hline 30 & 2.6210 & 0.22415 & 0.75123 & 33.094 & $1.047_{2}$ \\
\hline 35 & 2.5853 & 0.22873 & 0.74760 & 32.943 & $1.051_{9}$ \\
\hline 40 & 2.5497 & 0.23331 & 0.74387 & 32.770 & $1.056_{4}$ \\
\hline 45 & 2.5140 & 0.23788 & 0.74003 & 32.601 & $1.060_{7}$ \\
\hline 50 & 2.4784 & 0.24247 & 0.73609 & 32.427 & $1.064_{6}$ \\
\hline 55 & 2.4427 & 0.24704 & 0.73203 & 32.248 & $1.068_{4}$ \\
\hline
\end{tabular}

$\alpha=\mathrm{d}\left(\varepsilon_{12}-\varepsilon_{1}\right) / \mathrm{d} w, \beta=\mathrm{d}\left(\rho_{12}-\rho_{1}\right) / \mathrm{d} w, p_{2}$ is the specific polarization of the polymer, $P_{2}$ is the molecular polarization of a structural unit in the polymer, $\mu$ is the root mean square dipole moments calculated from the equation, $\mu=0.01281 \times\left\{\left(P_{2}-[M R]_{D}\right) T\right\}^{1 / 2}$. The value of the molecular refraction for the sodium $\mathrm{D}$ line $[M R]_{D}$, is $11.065 \mathrm{~mL}$. 


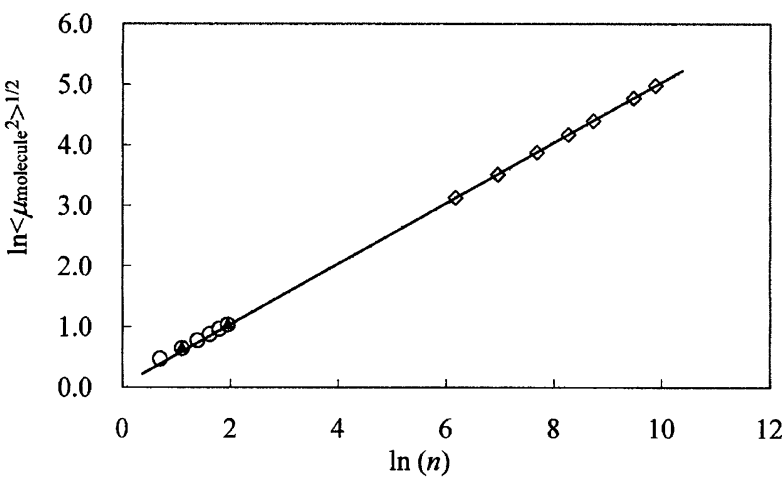

Figure 2. Double-logarithmic plots of the dipole moments $\left\langle\mu_{\text {molecule }}{ }^{2}\right\rangle^{1 / 2}$ vs. the repeating unit $n$ for poly(ethylene oxide) $(\diamond)$ in benzene at $25^{\circ} \mathrm{C}$ and PEO oligomers reported by Kotera et al. $(\bigcirc)$ at $25^{\circ} \mathrm{C}^{17}$ and Marchal et al. (A) at $20^{\circ} \mathrm{C} .{ }^{10}$

\section{DISCUSSION}

\section{Molecular Weight Dependence of Dipole Moment}

Figure 2 shows double-logarithmic plots of the root mean squared dipole moments for PEO $\left\langle\mu_{\text {molecule }}{ }^{2}\right\rangle^{1 / 2}$ in benzene at $25^{\circ} \mathrm{C}$ versus the degree of polymerization $n$, where $\mu_{\text {molecule }}$ is the dipole moment of the overall polymer chain, which is estimated by multiplying the average dipole moment per constitutional repeating unit $\left\langle\mu^{2}\right\rangle^{1 / 2}$ by the square root of the degree of polymerization $n^{1 / 2}$. The straight line is located by least-squares analysis for PEO and the slope is $0.499 \pm 0.001$. This result indicates that long-range excluded volume interactions do not influence the dipole moment of PEO in benzene, or if there is any influence, it is within the experimental error.

In Figure 2, the dipole moments of diethyl-terminated polyoxyethylene oligomers (PEO oligomer), $\mathrm{C}_{2} \mathrm{H}_{5} \mathrm{O}-$ $\left(\mathrm{C}_{2} \mathrm{H}_{4} \mathrm{O}\right)_{n}-\mathrm{C}_{2} \mathrm{H}_{5}$, reported by Kotera et al. $(n=1-6)^{17}$ and Marchal \& Benoit $(\mathrm{n}=2 \text { and } 6)^{10}$ in benzene are also plotted. Kotera et al. assumed the relation $P_{\mathrm{E}}+P_{\mathrm{A}}=1.1 \times[M R]_{\mathrm{D}}$ in Eq. (4), so the values plotted in the figure were recalculated by the relation $P_{\mathrm{E}}+P_{\mathrm{A}}=[M R]_{\mathrm{D}}$. The resulting line for PEO seems to be in accordance with the oligomers, but the slight upper deviation for small $n$ can not be overlooked, and will be discussed later.

\section{Dipole Moment Ratio $\left\langle\mu^{2}\right\rangle / m^{2}$}

Figure 3 shows the average dipole moment per constitutional repeating unit $\left\langle\mu^{2}\right\rangle^{1 / 2}$, for $\mathrm{RO}-\left(\mathrm{CH}_{2} \mathrm{CH}_{2} \mathrm{O}\right)_{n}-\mathrm{H}$ PEO in benzene at $25^{\circ} \mathrm{C}$, plotted against the logarithm of the number of repeating units $n$. In addition to the present results, values for the diethyl-terminated polyoxyethylene oligomers by Kotera et al. ${ }^{17}$ (in benzene at $25^{\circ} \mathrm{C}$ ) and by Marchal and Benoit ${ }^{10}$ (in benzene at $20^{\circ} \mathrm{C}$ ) are also presented. The average dipole moment per constitutional repeating unit, $\left\langle\mu^{2}\right\rangle^{1 / 2}$, for the oligomers was calculated using the relation, $\left\langle\mu^{2}\right\rangle^{1 / 2}=$ $\left(\left\langle\mu_{\text {molecule }}{ }^{2}\right\rangle / n\right)^{1 / 2}$. The value of $\left\langle\mu^{2}\right\rangle^{1 / 2}$ increases with the decrease in $n$, which is caused by the end group effect on the dipole moment. Extrapolation of the relation between $\left\langle\mu^{2}\right\rangle^{1 / 2}$

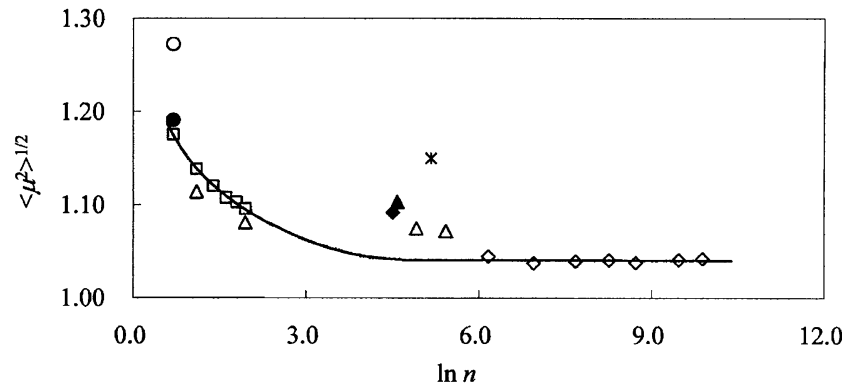

Figure 3. The root mean square dipole moments per constitutional repeating unit $\left\langle\mu^{2}\right\rangle^{1 / 2}$ as a function of the natural logarithm of $n$. poly(ethylene oxide) $(\diamond)$ and oligomers ${ }^{17}(\square), 1,2$-dimethoxyethane ${ }^{19}$ in 1,4-dioxane $(\bigcirc)$ and in toluene $(O)$ at $25^{\circ} \mathrm{C}$, POEG by Marchal et al. $(\triangle),{ }^{10}$ Riande $(\bullet),{ }^{11}$ Rossi et al. $(*)^{12}$ and Bak et al. $(\boldsymbol{\Delta})^{13}$ in benzene.

and $\mathrm{n}$ for oligomers to $n=0$ yields $\mu_{\mathrm{DE}}=1.20 \mathrm{D}$, which corresponds to the dipole moment of diethyl ether $\mathrm{C}_{2} \mathrm{H}_{5}-\mathrm{O}-$ $\mathrm{C}_{2} \mathrm{H}_{5}$ (DE) in benzene. The value is intermediate between other observed dipole moments, which range from $1.17 \mathrm{D}$ to $1.28 \mathrm{D}$, as summarized in the tables published by McCellan ${ }^{18}$ for diethyl ether in benzene at $25^{\circ} \mathrm{C}$. Figure 3 also includes the values for poly(ethylene glycol) (POEG), $\mathrm{HO}-\left(\mathrm{CH}_{2} \mathrm{CH}_{2} \mathrm{O}\right)_{n}-$ $\mathrm{H}$, reported by Marchal \& Benoit $(n=136,227$, in benzene at $\left.20^{\circ} \mathrm{C}\right),{ }^{10}$ Riande $\left(M_{\mathrm{w}}=4000\right.$, in benzene at $\left.20^{\circ} \mathrm{C}\right),{ }^{11}$ Rossi \& Magnasco $\left(n=176 \text {, in benzene at } 25^{\circ} \mathrm{C}\right)^{12}$ and Bak et al. $\left(n=97.8\right.$, in benzene at $\left.20^{\circ} \mathrm{C}\right) .{ }^{13}$ Evidently, these values are considerably larger than those for the PEOs.

As previously reported, ${ }^{14,21}$ two different methods were used for evaluation of the dipole moments of polymers in solution. In this paper, the authors evaluated the dipole moments of the polymers based on measurements of the dielectric constants and densities of the polymer solutions, using eqs (1-5) (Halverstadt-Kumler-Debye method, (H-K-D) method ${ }^{15,16}$ ). On the other hand, the cited data in Figure 3 were evaluated using the Guggenheim-Smith equations (G-S method), ${ }^{26}$ with the exception of the data from Kotera et al., in which $\mu$ was estimated based on measurements of the dielectric constants $\varepsilon$ and the refractive indices $n$ of the solutions. Both of these methods are based on the Debye theory, but the assumptions used for estimating $P_{\mathrm{E}}+P_{\mathrm{A}}$ differ between the respective methods. We have previously examined the discrepancy between these two methods, ${ }^{14,21}$ and can summarize our conclusions as follows; if the solvent has a small value of $\varepsilon-n^{2}$, as in the case of benzene with a value of $\varepsilon-n^{2}=$ 0.022 at $25^{\circ} \mathrm{C}$, then the G-S method provides almost equivalent results to those obtained using the H-K-D method. ${ }^{14,15,21}$

The discrepancy that appears in Figure 3 may be a result of the $\mathrm{OH}$ group at the end of the molecule; the bond dipole moment of the $\mathrm{OH}$ group $\left(m_{\mathrm{O}-\mathrm{H}}=1.7 \mathrm{D}\right)$ is larger than that of the $\mathrm{C}-\mathrm{O}\left(m_{\mathrm{C}-\mathrm{O}}=1.07 \mathrm{D}\right)$ bond. The PEO chains used in this study have an $\mathrm{OH}$ group on one chain end. On the other hand, the POEG chains have $\mathrm{OH}$ groups on both chain ends, and furthermore, the chains have a smaller number of repeating units. The value observed for PEO-2 was slightly high; the $M_{\mathrm{w}}$ 
of PEO-2 is the smallest $\left(2.1 \times 10^{4}, n=477\right)$ among the PEO samples, which may suggest that the $\mathrm{OH}$ end groups influence the observed dipole moment.

The following dipole moments per constitutional repeating unit $\left\langle\mu^{2}\right\rangle^{1 / 2}$, for PEO samples in benzene at $25^{\circ} \mathrm{C}$ were obtained: $1.046_{5} \mathrm{D}$ (PEO-2), 1.037 2 D (PEO-5), $1.039_{3} \mathrm{D}$ (PEO-10), 1.040 5 D (PEO-17), 1.037 7 D (PEO-27), 1.040 8 (PEO-57), and $1.042_{1} \mathrm{D}$ (PEO-86). At $55^{\circ} \mathrm{C}$ the values are $1.076_{8} \mathrm{D}$ (PEO-2), 1.071 $\mathrm{D}$ (PEO-5), 1.066 2 D (PEO-10), $1.079_{5} \mathrm{D}$ (PEO-17), 1.068 4 D (PEO-27), 1.076 ${ }_{8} \mathrm{D}$ (PEO-57) and $1.068_{4} \mathrm{D}$ (PEO-86), where $\mathrm{D}$ indicates the debye unit. The root mean-square average of $\left\langle\mu^{2}\right\rangle^{1 / 2}$ for all the PEO samples in benzene is calculated as $1.040 \pm 0.002$ [D] at $25^{\circ} \mathrm{C}$ and $1.072 \pm 0.005[\mathrm{D}]$ at $55^{\circ} \mathrm{C}$. These results indicate that the measurements were obtained with good accuracy at $25^{\circ} \mathrm{C}$, but this accuracy drops slightly at higher temperatures.

The measured dipole moment of the polymers $\left\langle\mu_{\text {molecule }}{ }^{2}\right\rangle$ is the mean square statistical average of the vector sums of the dipoles located along the chain. Therefore the dipole moment ratio, $\left\langle\mu_{\text {molecule }}{ }^{2}\right\rangle / \mathrm{nm}^{2}$, is one of the most important parameters used in the conformational analysis of polymer chains, where $n$ is the number of structural repeating units and $m$ is the unit moment. The dipole moment ratio $\left\langle\mu_{\text {molecule }}{ }^{2}\right\rangle / \mathrm{nm}^{2}=\left\langle\mu^{2}\right\rangle / \mathrm{m}^{2}$ in this study is calculated as $0.472 \pm 0.002$ for PEO in benzene at $25^{\circ} \mathrm{C}$, where the unit moment $m$ is estimated on the basis of bond moments, $m_{\mathrm{C}-\mathrm{O}}=1.07 \mathrm{D}$ and $m_{\mathrm{C}-\mathrm{C}}=0 \mathrm{D}$, using the equation, ${ }^{5,6} m^{2}=\left(m_{\mathrm{C}-\mathrm{O}}{ }^{2} \times 2+m_{\mathrm{C}-\mathrm{C}} \times 1\right)$. Taking the value of $\mu_{\mathrm{DE}}=1.20 \mathrm{D}$, a dipole moment ratio of $\mathrm{PEO}$ in benzene $\left\langle\mu^{2}\right\rangle / \mu_{\mathrm{DE}}{ }^{2}$ of 0.746 at $25^{\circ} \mathrm{C}$ is obtained, which is a factor that is dependent on the degree of flexibility in the polymeric chains. In previous studies, ${ }^{20,21}$ we have reported the dipole moment ratios $\left\langle\mu^{2}\right\rangle / \mu_{\mathrm{o}}{ }^{2}$ of poly(4-bromostyrene) (PBrSt) as follows: $\left\langle\mu^{2}\right\rangle / \mu_{\mathrm{o}}{ }^{2}$ of 0.467 in benzene and 0.459 in $1,4-$ dioxane at $25^{\circ} \mathrm{C}$, where $\mu_{\mathrm{o}}$ is the dipole moment of 4bromoethylbenzene (4-BrEtBz), a monomeric model compound of $\mathrm{PBrSt}\left(\left\langle\mu^{2}\right\rangle^{1 / 2}=1.371 \mathrm{D}\right.$ and $\mu_{\mathrm{o}}=2.007 \mathrm{D}$ in benzene at $25^{\circ} \mathrm{C},\left\langle\mu^{2}\right\rangle^{1 / 2}=1.413 \mathrm{D}$ and $\mu_{\mathrm{o}}=2.0867 \mathrm{D}$ in 1,4-dioxane at $25^{\circ} \mathrm{C}$ ). This shows that PEO chains have a larger degree of freedom in rotation about the chain bonds than PBrSt chains.

\section{Dipole Moment of 1,2-Dimethoxy Ethane and 1,2-Diethoxy Ethane}

Before consideration of the PEO polymer is advanced, the dipole moments of PEO model compounds, 1,2-dimethoxyethane (DME) and 1,2-diethoxyethane (DEE) are discussed.

In Figure 3, the dipole moments $\left\langle\mu^{2}\right\rangle^{1 / 2}$ of DME observed in toluene and 1,4-dioxane at $25^{\circ} \mathrm{C}^{19}$ are also shown. It is apparent from the figure, that the $\left\langle\mu^{2}\right\rangle^{1 / 2}$ value in 1,4-dioxane $(1.800 \mathrm{D})$ is considerably larger than that in toluene $(1.684 \mathrm{D})$. We have previously reported ${ }^{20,21}$ that the dipole moments of polymers and their model compound molecules are slightly different and dependent on the solvent, but this cause should not be influenced by excluded volume interaction; $\left\langle\mu^{2}\right\rangle^{1 / 2}$ is smaller if the dielectric constant $\varepsilon$ of the solvent used for the measurements is larger. A possible explanation for such a solvent effect suggested by Higashi, ${ }^{22}$ Tonelli et al., ${ }^{23}$ and Baysal $^{24}$ is based on a specific local interaction between solvent and solute molecules, which may influence the local conformation of the solute molecule. The difference between the observed dipole moments of DME may be due to such a specific local interaction that depends on the nature of the solvent. Recently, Rudan-Tasic and Klofutar ${ }^{25}$ reported that dipole moments of poly(oxyethylene) glycol oligomers determined in benzene and 1,4-dioxane on the basis of the Debye method do not show any appreciable solvent dependence. This conclusion is not in agreement with the present results.

Figure 3 also shows that $\left\langle\mu^{2}\right\rangle^{1 / 2}$ for DME are larger than that for DEE in benzene. Considering that the dielectric constant of benzene $(\varepsilon=2.2742)$ is intermediate between 1,4dioxane $(\varepsilon=2.2061)$ and toluene $(\varepsilon=2.3762)$ and both DME and DEE have same polar chemical structure, it seems reasonable that $\left\langle\mu^{2}\right\rangle^{1 / 2}$ for DME in toluene should be smaller than that for DEE in benzene. The results shown in Figure 3 suggest that this is not only due to the solvent $\varepsilon$ effect, but presumably reflects differences in the inherent conformational characteristics between the end groups; methyl-group of DME and ethyl-group of DEE.

\section{Temperature Dependence of Dipole Moment}

Figure 4 shows the average dipole moments per constitutional repeating unit, $\left\langle\mu^{2}\right\rangle^{1 / 2}$, for PEO in benzene as function of temperature. The temperature dependence, $\mathrm{d}\left(\ln \left\langle\mu^{2}\right\rangle\right) / \mathrm{d} T$, is also an important parameter related to the conformation of the polymer chains, in particular, the energy of the bond conformation. From Table II(a-g), the dipole moments increase gradually with temperature: however, Figure 4 shows a more detailed aspect of the temperature dependence of $\left\langle\mu^{2}\right\rangle^{1 / 2}$; the dipole moments do not increase linearly, but the rate of $\left\langle\mu^{2}\right\rangle^{1 / 2}$ increase slows down slightly at higher temperatures. The temperature coefficient $\left(\ln \left\langle\mu^{2}\right\rangle\right) / \mathrm{d} T$, estimated by the least-squares method in the temperature range from 25 to $45^{\circ} \mathrm{C}$, are listed in Table III. The value of $\mathrm{d}\left(\ln \left\langle\mu^{2}\right\rangle\right) / \mathrm{d} T$ for the respective polymers are obtained with good accuracy, but there is still considerable difference in the $\mathrm{d}\left(\ln \left\langle\mu^{2}\right\rangle\right) / \mathrm{d} T$ values

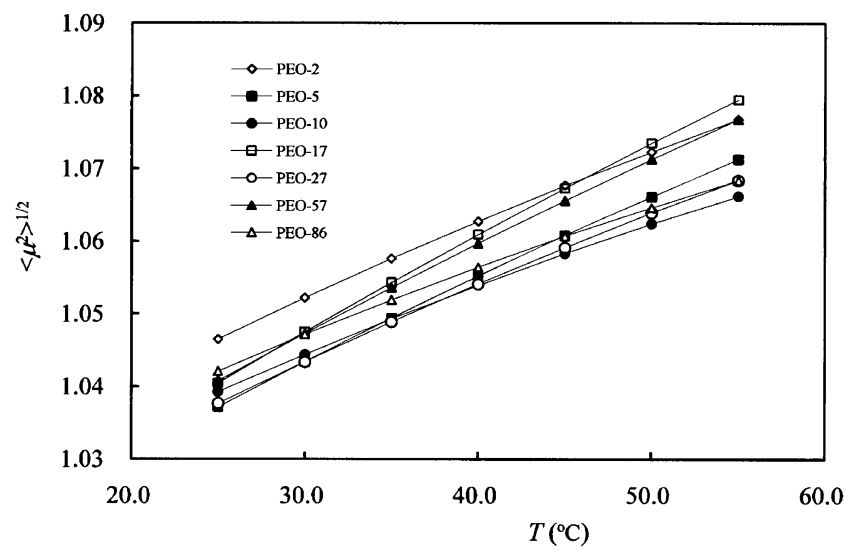

Figure 4. Temperature dependence of the dipole moments $\left\langle\mu^{2}\right\rangle^{1 / 2}$ for poly(ethylene oxide) in benzene. 
Table III. Temperature coefficients of the dipole moments for PEO in benzene

\begin{tabular}{cc}
\hline Code & $10^{3} \mathrm{~d}\left(\ln \left\langle\mu^{2}\right\rangle\right) / \mathrm{d} T$ \\
\hline PEO-2 & $2.20 \pm 0.03$ \\
PEO-5 & $2.24 \pm 0.03$ \\
PEO-10 & $1.81 \pm 0.03$ \\
PEO-17 & $2.54 \pm 0.03$ \\
PEO-27 & $2.04 \pm 0.03$ \\
PEO-57 & $2.35 \pm 0.03$ \\
PEO-86 & $1.77 \pm 0.04$ \\
\hline
\end{tabular}

among the polymers. Using the least-squares method, the averaged value of the temperature dependence for all samples was calculated as $\mathrm{d}\left(\ln \left\langle\mu^{2}\right\rangle\right) / \mathrm{d} T=(2.11 \pm 0.28) \times 10^{-3} \mathrm{~K}^{-1}$. The temperature dependence is slightly smaller when it is calculated including values up to a higher temperature range.

Since Flory, Abe and Mark ${ }^{6,25}$ proposed the three-state rotational isomeric state (RIS) model, statistical studies on the conformations of polymer chains have been carried out. ${ }^{7-9}$ In their earlier approaches, the conformational energy parameters and the statistical weight of the three-state RIS model were estimated using conventional semi-empirical expressions. The first- and second-order statistical weights used to describe the interactions between atoms and groups separated by three or four bonds were determined and then corrected so as to yield the best agreement between calculated and experimental results such as the mean-square chain dimensions, dipole moment and their temperature dependence. For PEO chains, Abe and Mark ${ }^{5}$ proposed the values for the first-order interaction energies of the gauche state $\mathrm{g}^{ \pm}$relative to the trans as $E_{\sigma}=-0.5$ $\mathrm{kcal} \mathrm{mol}^{-1}$ around the $\mathrm{C}-\mathrm{C}$ bond and $E_{\rho}=0.90 \mathrm{kcal} \mathrm{mol}^{-1}$ around the $\mathrm{O}-\mathrm{C}$ or $\mathrm{C}-\mathrm{O}$ bonds. For the second-order interaction energy, occurring in the $\mathrm{g}^{ \pm} \mathrm{g}^{\mp}$ state conformation for the $\mathrm{O}-\mathrm{C} / \mathrm{C}-\mathrm{C}$ bond pair, $E_{\omega}=0.40 \mathrm{kcal} \mathrm{mol}^{-1}$ was given. From these energies, the configuration-dependent properties of PEO were given as, $\left\langle\mu^{2}\right\rangle / m^{2}=0.49$ and $\mathrm{d}\left(\ln \left\langle\mu^{2}\right\rangle\right) / \mathrm{d} T=2.9 \times$ $10^{-3} \mathrm{~K}^{-1}$. In recent work by Tasaki et al., ${ }^{7}$ the conformational energies of PEO chains were estimated from ${ }^{1} \mathrm{H}$ and ${ }^{13} \mathrm{C}$ NMR studies on PEO and DME, to be $\left\langle\mu^{2}\right\rangle / m^{2}=0.35$ and $\mathrm{d}\left(\ln \left\langle\mu^{2}\right\rangle\right) / \mathrm{d} T=3.0 \times 10^{-3} \mathrm{~K}^{-1}$. It was shown that $\left\langle\mu^{2}\right\rangle / m^{2}$ varies most sensitively with $E_{\rho} ;\left\langle\mu^{2}\right\rangle / m^{2}$ becomes larger with lowering $E_{\rho}$, but moderately with the other parameters and $E_{\sigma}$ varies depending on the solvent polarity (e.g., $E_{\sigma}=$ $-0.5 \mathrm{kcal} \mathrm{mol}^{-1}$ in $c-\mathrm{C}_{6} \mathrm{D}_{12}$ and $-1.2 \mathrm{kcal} \mathrm{mol}^{-1}$ in $\left.\mathrm{D}_{2} \mathrm{O}\right)$.

In more recent work, ${ }^{8,9}$ the energy parameters for the RIS model were estimated from $a b$ initio molecular orbital (MO) calculations of the oligomeric model compound for the PEO chain and were then adjusted so as to agree with the experimental data, such as NMR vicinal coupling constants of the model compound. Smith et $a .^{8}$ determined the conformational energy parameters, based on $a b$ initio electronic structure analysis of a model molecule, DME. They suggested that the attractive $\mathrm{O} \cdots \mathrm{H}$ interactions between the non-bonded $\mathrm{O}$ and $\mathrm{H}$ atoms results in lowering of the intrinsic $-\mathrm{O}-\mathrm{C}-\mathrm{C}-\mathrm{O}-$ gauche torsion energy, so that the third-order interactions occurring in the $\mathrm{g}^{ \pm} \mathrm{g}^{ \pm} \mathrm{g}^{ \pm}$conformation of DME should be included in the RIS calculations. Using a new thirdorder RIS model with these energies, they reported $\left\langle\mu^{2}\right\rangle / m^{2}=$ $0.27-0.29$ and $\mathrm{d}\left(\ln \left\langle\mu^{2}\right\rangle\right) / \mathrm{d} T=1.9-2.4 \times 10^{-3} \mathrm{~K}^{-1}$ for PEO. The results are an agreement with the experimental results for $\mathrm{PEO}$, if the unusually large value of $1.43 \mathrm{D}$ is used for the bond moment of $\mathrm{C}-\mathrm{O} m_{\mathrm{C}-\mathrm{O}}$, instead of the conventional value of $1.07 \mathrm{D}$.

Sasanuma et al. ${ }^{9}$ investigated the conformational characteristics of PEO and DME using $a b$ initio MO calculations and showed that the first-order interaction around the $\mathrm{C}-\mathrm{C}$ bond of DME $E_{\sigma}$ has a large solvent dependence, that is, $E_{\sigma}$ is positive in the gaseous state, but negative in non-polar solvent, whereas $E_{\rho}$ does not display an explicit solvent dependence. For the second-order interaction $E_{\omega}$, a low energy value was evaluated, because of the $(\mathrm{C}-\mathrm{O}) \cdots \mathrm{H}$ attraction occurring in the $\operatorname{tg}^{ \pm} \mathrm{g}^{\mp}$ conformations of the $-\mathrm{O}-\mathrm{C}-\mathrm{C}-\mathrm{O}-$ bond. The conformational energy of PEO in non-polar organic solvents was simulated so as to yield the best agreement with the experimental data $\left(\left\langle\mu^{2}\right\rangle / m^{2}=0.41, m_{\mathrm{C}-\mathrm{O}}=1.18 \mathrm{D}\right.$ in benzene $) ; E_{\sigma}=-0.25$ $\mathrm{kcal} \mathrm{mol}{ }^{-1}, E_{\rho}=1.17 \mathrm{kcal} \mathrm{mol}^{-1}$, and $E_{\omega}=-0.79 \mathrm{kcal} \mathrm{mol}^{-1}$, which resulted in $\mathrm{d}\left(\ln \left\langle\mu^{2}\right\rangle\right) / \mathrm{d} T=1.9 \times 10^{-3} \mathrm{~K}^{-1}$. Sasanuma et al. did not include the third-order interaction energies, because the short $\mathrm{C}-\mathrm{O}$ bond does not allow $\mathrm{g}^{ \pm} \mathrm{g}^{ \pm} \mathrm{g}^{ \pm}$conformational sequences to be present in PEO.

The experimental results for PEO in benzene were compared with these RIS calculations. The value of $\mathrm{d}\left(\ln \left\langle\mu^{2}\right\rangle\right) /$ $\mathrm{d} T=(2.1 \pm 0.3) \times 10^{-3} \mathrm{~K}^{-1}$ averaged over all PEO samples in the temperature range from 25 to $45^{\circ} \mathrm{C}$ showed good coincidence with the RIS calculations by Sasanuma et al..$^{9}$ and/ or by Smith et al. ${ }^{8}$ However, the experimental results for $\left\langle\mu^{2}\right\rangle / m^{2}$ do not agree well with their calculations. When evaluating the dipole moment ratio experimentally, the bond dipole moment $\mathrm{m}_{\mathrm{C}-\mathrm{O}}$ is required in the denominator of the equation. Various values for $m_{\mathrm{C}-\mathrm{O}}$ are with considerable variation have been proposed, some of are $\mathrm{m}_{\mathrm{C}-\mathrm{O}}=1.07 \mathrm{D},{ }^{5,6}$ $1.18 \mathrm{D}^{9}$ or $1.43 \mathrm{D}^{8}$ When the bond dipole moment is estimated from $\mu_{\mathrm{DE}}=1.20 \mathrm{D}$, as estimated in the previous section for diethyl ether in benzene at $25^{\circ} \mathrm{C}$, the bond dipole moment would be $m_{\mathrm{C}-\mathrm{O}}=1.07 \mathrm{D}$ based on bond angle $\angle \mathrm{COC}=$ $111.5^{\circ}$. The value $m_{\mathrm{C}-\mathrm{O}}=1.07 \mathrm{D}$ was then used for the calculation and $\left\langle\mu^{2}\right\rangle / m^{2}$ of $0.472 \pm 0.002$ was obtained for PEO in benzene. It could be concluded that $\left\langle\mu^{2}\right\rangle / m^{2}=0.47$ with an uncertainty of rather less than \pm 0.01 for PEO in benzene at $25^{\circ} \mathrm{C}$. The value agrees fairly well with the earlier studies by Abe \& Mark. ${ }^{5}$ The discrepancy between the improved RIS calculations for $\left\langle\mu^{2}\right\rangle / m^{2}$ and the experimental results cannot be explained; however, the PEO chains may assume a predominantly gauche conformation, even in nonpolar benzene solution, and, consequently, a lower value of $E_{\rho}$ should be assumed for PEO chains. The $\pi$-electron system of benzene molecules may stabilize the gauche conformation of PEO chains. Furthermore, the configuration-dependent properties obtained for $\mathrm{DME}^{19}$ were as follows, $\left\langle\mu_{\mathrm{DME}}{ }^{2}\right\rangle / \mathrm{nm}^{2}=$ 0.707 (at $25^{\circ} \mathrm{C}$ ) and $\mathrm{d}\left(\ln \left\langle\mu_{\mathrm{DME}^{2}}{ }^{2}\right\rangle\right) / \mathrm{d} T=0.80 \times 10^{-3} \mathrm{~K}^{-1}$ in 1,4-dioxane $(\varepsilon=2.2061)$ and $\left\langle\mu_{\mathrm{DME}^{2}}{ }^{2} / \mathrm{nm}^{2}=0.619 \quad\right.$ at $\left.25^{\circ} \mathrm{C}\right)$ and $\mathrm{d}\left(\ln \left\langle\mu_{\mathrm{DME}}{ }^{2}\right\rangle\right) / \mathrm{d} T=0.82 \times 10^{-3} \mathrm{~K}^{-1}$ in toluene 
$(\varepsilon=2.3762)$. The dipole moment ratios and temperature dependence for DME in both solvents disagree with the MO calculations proposed by Sasanuma et al. $\left(\left\langle\mu_{\mathrm{DME}}{ }^{2}\right\rangle / \mathrm{nm}^{2}=\right.$ 0.34 and $\left.\mathrm{d}\left(\ln \left\langle\mu_{\mathrm{DME}^{2}}\right\rangle\right) / \mathrm{d} T=2.2 \times 10^{-3} \mathrm{~K}^{-1}\right)$. It has already been shown in Figure 3, the dipole moments per repeating unit of DME are considerably larger than those of PEO; therefore $\left\langle\mu_{\mathrm{DME}}{ }^{2}\right\rangle / n m^{2}$ and $\mathrm{d}\left(\ln \left\langle\mu_{\mathrm{DME}}{ }^{2}\right\rangle\right) / \mathrm{d} T$ are expected to be respectively larger and smaller than those for PEO chains.

Received: September 28, 2008 Accepted: April 7, 2009 Published: June 10, 2009

\section{REFERENCES}

1. Q. W. Yuan, in "Polymer Data Handbook," J. E. Mark, Ed., Oxford University Press, New York, 1999.

2. P. J. Flory, "Statistical Mechanics of Chain Molecules," Interscience Publishers, New York, 1969.

3. P. Debye and F. Bueche, J. Chem. Phys., 19, 589 (1951).

4. a) W. H. Stockmayer, Pure Appl. Chem., 15, 539 (1967).

b) K. Nagai and T. Ishikawa, Polym. J., 2, 416 (1971).

c) M. Doi, Polym. J., 3, 252 (1972).

d) W. L. Mattice and D. K. Carpenter, Macromolecules, 17, 625 (1984).

e) W. L. Mattice, D. K. Carpenter, M. D. Barkley, and N. R. Kestner, Macromolecules, 18, 2236 (1985).

f) M. L. Mansfield, Macromolecules, 19, 1427 (1986).

5. J. E. Mark and P. J. Flory, J. Am. Chem. Soc., 88, 3702 (1966).

6. A. Abe and J. E. Mark, J. Am. Chem. Soc., 98, 6468 (1976).

7. a) K. Tasaki and A. Abe, Polym. J., 17, 641 (1985). b) A. Abe, K. Tasaki, and J. E. Mark, Polym. J., 17, 883 (1985).

8. D. Smith, D. Y. Yoon, and R. L. Jaffe, Macromolecules, 26, 5213 (1993).

9. Y. Sasanuma, H. Ohta, I. Touma, H. Matoba, Y. Hayashi, and A. Kaito, Macromolecules, 35, 3748 (2002).

10. a) J. Marchal and H. Benoit, J. Polym. Sci., Part A: Polym. Chem., 23, 223 (1957)

b) J. Marchal and H. Benoit, J. Chim. Phys., 52, 818 (1955).

11. E. Riande, J. Polym. Sci., Part B: Polym. Phys., 14, 2231 (1976).

12. C. Rossi and V. Magnasco, J. Polym. Sci., Part A: Polym. Chem., 58, 977 (1962).

13. K. Bak, G. Elefante, and J. E. Mark, J. Phys. Chem., 71, 4007 (1967).

14. N. Yamaguchi, M. Sato, and M. Shima, Polym. J., 20, 97 (1988).

15. P. Debye, "Polar Molecules," Chemical Catalog, New York, 1929.

16. I. F. Halverstadt and W. D. Kumler, J. Am. Cham. Soc., 64, 2988 (1942).

17. A. Kotera, K. Suzuki, K. Matsumura, T. Nakano, T. Oyama, and U. Kambayashi, Bull. Chem. Soc. Jpn., 35, 797 (1962).

18. A. L. McClellan, "Tables of Experimental Dipole Moments," W. H. Freeman and Company, 1963.

19. M. Sato and N. Yamaguchi, Sci. Rept. Tokyo Woman's Chrisitan Univ., 58, 1887 (2007).

20. M. Sato, N. Yamaguchi, and M. Shima, Polym. J., 23, 735 (1991).

21. M. Shima, N. Yamaguchi, and M. Sato, Makromol. Chem., 192, 531 (1991).

22. K. Higashi, Sci. Pap. Inst. Phys. and Chem. Res., (Tokyo), 28, 284 (1936).

23. A. E. Tonelli and L. A. Belfiore, Macromolecules, 16, 1740 (1983).

24. I. Bahar, B. M. Baysal, and B. Erman, Macromolecules, 19, 1703 (1986).

25. D. Rudan-Tasic and C. Klofutar, Monatsh. Chem., 136, 1171 (2005).

26. a) E. A. Guggenheim, Trans. Faraday Soc., 45, 714 (1949).

b) E. A. Guggenheim, Trans. Faraday Soc., 47, 573 (1951).

c) J. W. Smith, Trans. Faraday Soc., 46, 394 (1950). 